\title{
Use of pineapple waste for production of decomposable pots
}

\author{
I. Jirapornvaree ${ }^{1}$ (I) T. Suppadit ${ }^{2} \cdot$ A. Popan $^{3}$
}

Received: 7 June 2017/ Accepted: 23 October 2017/Published online: 28 October 2017

(c) The Author(s) 2017. This article is an open access publication

\begin{abstract}
Purpose The aim of this research was to evaluate the suitability of pineapple waste for production of decomposable nursery pots.

Methods The experiment was completely randomized, with three replicates and eighteen formula treatments. Treatments consisted of varying ratios of pineapple waste to binder, including 2:1, 1:0 (fresh pineapple waste), 1:1, $1: 1.5$, and $1: 2$; the textures tested were coarse, medium, and fine, and the pot thicknesses were $0.5,1.0$ and $1.5 \mathrm{~cm}$. Results The results revealed that the physical and chemical properties of pineapple waste were suitable for use in nursery pots on an experimental scale. The optimal physical and chemical properties for a decomposable pot included a 1:0 ratio of pineapple waste to binder, a coarse structure, and a pot thickness of $1 \mathrm{~cm}$. With these properties, the pot degraded in more than 45 days, $\mathrm{N}$ and $\mathrm{P}$ release rates were $0.49 \%$ and $7.97 \mathrm{mg}-\mathrm{P} / \mathrm{kg}$, respectively,
\end{abstract}

I. Jirapornvaree

ittisakji@gmail.com

T. Suppadit

tawatc.s@nida.ac.th

A. Popan

Apisakp9@gmail.com

1 Center for Competitiveness Research, Research Center, National Institute of Development Administration, Bangkok 10240, Thailand

2 Graduate School of Environmental Development Administration, National Institute of Development Administration, Bangkok 10240, Thailand

3 Department of Soil Resource and Environmental Management, Faculty of Agriculture Technology, King Mongkut's Institute of Technology Ladkrabang, Bangkok 10520, Thailand and the average absorption rate was $258.43 \%$. Saturation occurred in $45 \mathrm{~min}$, and the water evaporated in $444 \mathrm{~h}$. Conclusion In terms of cost production per pot, fresh pineapple waste cost 0.0075 USD for a three-and-a-half inch diameter decomposable pot (excluding logistical costs). Therefore, this study provides a possible method for waste management.

Keywords Agricultural waste $\cdot$ Eco-product $\cdot$ Pineapple cannery industry $\cdot$ Waste management

\section{Introduction}

Sustainable development has been defined in many ways to develop industrial sustainability to move toward a lowcarbon society. Thailand's economic growth in the past two decades has dramatically increased consumption of natural resources in the industrial, agricultural, and household sectors. The 2015 Thailand state of pollution report found that the quantity of hazardous waste in the country was 3.445 million tons. The contribution of Thailand's industrial sector was 2.8 million tons, or $81.5 \%$. At present, the use of recycled materials is a major trend in industrial waste management (Chandak 2010).

In 2015, there were approximately 13.60 million tons of recyclable industrial waste consisting of glass, paper, plastic, steel, aluminum and rubber. Of that, approximately 8.20 million tons or $65.73 \%$ were either re-processed/ reused (3.55 million tons or $43.29 \%$ ) or supplied to the waste exchange system (3.45 million tons or $42.07 \%$ ). Compared with 2014, usage of recyclable industrial waste decreased by 1\% (Pollution Control Department 2015).

The pineapple industry in Thailand is now the fourth largest producer and exporter of pineapple in the world 
(Office of Agricultural Economics 2016). Average annual production is 1.79 million tons (Food Intelligence Center Thailand 2015). Currently, Thailand has 75 pineapple processing companies that generate approximately 200 tons of waste per day (Ritthisorn et al. 2016). Thus, studies have focused on producing things such as fertilizer and calcareous soil improvement (Ch'ng et al. 2013; Thongpae et al. 1992), animal food (Youburee 2003), and supplementary food from pineapple fiber extraction (Upadhyay et al. 2010; Utama-ang and Tepjaikad 2001).

Therefore, this study aimed to use pineapple waste from the cannery industry to produce decomposable pots, with the hope of replacing plastic plant nursery bags and reducing waste. Moreover, this method provides an alternative usage for pineapple waste and adds value to the byproduct. It also aligns with current trends in ecologically sustainable products.

\section{Materials and methods}

\section{Preparation of pineapple waste and binder}

1. The pineapple waste was baked for $24 \mathrm{~h}$ at temperatures between 65 and $75^{\circ} \mathrm{C}$.

2. The pineapple waste was ground so that coarse, medium, and fine textures could be tested.

3. The binder was prepared with a 1:5 ratio of tapioca starch to water.

4. The pineapple waste was mixed with binder.

\section{Experimental design}

1. To produce the decomposable pots, ratios of pineapple waste to binder tested were 2:1, 1:0 (fresh pineapple waste), $1: 1,1: 1.5,1: 2$ and $1: 3$, along with pot thicknesses of $0.5,1.0$ and $1.5 \mathrm{~cm}$. Then, the pots were baked at approximately $65^{\circ} \mathrm{C}$ for $12 \mathrm{~h}$.

2. Soil was packed into the decomposable pots.

3. The experimental design was completely randomized (CRD).

4. Pots were regularly watered every day, one at a time, with the same amount of liquid. Observations were made, and watering was stopped when decomposable pots were broken beyond repair.

5. Total Kjeldahl nitrogen (TKN) was determined after digesting the sample with concentrated $\mathrm{H}_{2} \mathrm{SO}_{4}$ (1:20, w/v) followed by distillation and titration (Bremner and Mulvaney 1982). Total phosphorus was analyzed from the wet digest $\left(\mathrm{HClO}_{4}\right)$ and was estimated by the colorimetric method using ammonium molybdate in hydrochloric acid. Absorption rate was measured by weighed and recorded the value of each pot that was immersed in water every 5 min until saturation point and evaporation rate was measured by recorded the changed weight of saturated pot every $12 \mathrm{~h}$ until the weight of the pot was reached the same as initial weight of dry pot (Krinara 2011).

\section{Data analysis}

The data were analyzed using an $F$ test (One-way Analysis of Variance) and SAS software. SAS System version 9.0 for Windows was used to test for differences between factors.

\section{Results and discussion}

\section{Physical and chemical properties of pineapple waste}

Table 1 shows that $\mathrm{pH}$ of the pineapple waste was neutral over time (Perez et al. 1973). Electrical conductivity was low, and the salt and moisture levels of pineapple waste were suitable for manufacturing decomposable pots. Total nitrogen remained at moderate levels and could be used as fertilizer for the plant (Espinosa et al. 2012). Total phosphorus was low (relative to phosphorus in the soil), and additional fertilizer could be added to nourish the plant. Thus, pineapple waste was suitable to be used as material for research (Schettinia et al. 2013).

\section{Ratio of tapioca starch and water in binder production}

This study found that a suitable ratio of binder to tapioca starch ranged from 1:1 to 1:9. However, the most costeffective ratio of binder to tapioca starch was $1: 5$, followed by $1: 6$ and $1: 7$. Ratios of $1: 1,1: 2$ and $1: 3$ were the least cost-effective. Therefore, this study recommended using a 1:5:1 ratio of tapioca starch to water to pineapple waste for conducting experiments and developing a product (Leach 1965; Srirod and Piyachomkwan 2003).

Table 1 Physical and chemical properties of pineapple waste

\begin{tabular}{lcl}
\hline Physical and chemical properties & Before & After \\
\hline $\mathrm{pH}$ & 6.96 & 5.93 \\
Electrical conductivity; EC $(\mu \mathrm{S})$ & 1.87 & 3.57 \\
Moisture $(\%)$ & 70.94 & - \\
Total nitrogen; TN $(\%)$ & 0.56 & 0.31 \\
Total phosphorus; TP (mg-P/kg) & 6.14 & 6.10 \\
\hline
\end{tabular}




\section{Optimum size of pineapple waste texture in decomposable pot production}

Pineapple waste textures can be categorized into coarse, medium and fine, as shown in Fig. 1.

Table 2 shows that the sizes of pineapple waste textures influenced the production of pots. The coarse texture and the waste condition resemble a fabric weave after production. The resulting strength of the coarse-texture pot was the most appropriate (Sopunna et al. 2015; Sukaneeyuth et al. 2014). This study found that coarse pineapple waste of any ratio can be molded into product. The medium size texture was less suitable, as the binding was relatively soft. In contrast, the fine-textured pineapple waste was the least appropriate texture because of its production costs.

\section{Optimum thickness of decomposable pots}

Thickness was tested by producing decomposable pots using the procedure in steps 1 through 5 (different thicknesses used in step 5 included $0.5,1.0,1.5,2.0$ and $2.5 \mathrm{~cm})$. Then, the pot was filled with soil, and performance was analyzed.

This study found that decomposable pots with thicknesses of $0.5,1.0$ and $1.5 \mathrm{~cm}$ could be formed and filled with soil, as shown in Fig. 2. Conversely, pots with thicknesses of 2.0 and $2.5 \mathrm{~cm}$ could be produced, but their resulting volume was not suitable for holding soil.

\section{Nutrient release during degradation; absorption and evaporation properties of decomposable pots}

\section{Ratio of degradation}

Study of nutrient release during degradation indicated that the optimum degradation time of a nursery pot was more than 45 days, as shown in Table 3. In other words, the degradation rate was the time to decomposition within a defined period. A total of 15 formulas, such as 1:2 and 1:0 (pineapple waste:binder) satisfied this optimum condition, although a 1:1 ratio could only be tested with a coarse

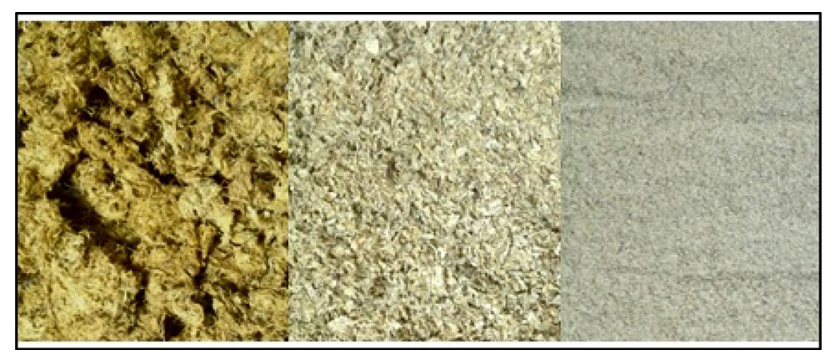

Fig. 1 Size of pineapple waste textures, from left: coarse, medium, and fine
Table 2 Forming size capabilities of pineapple waste textures

\begin{tabular}{|c|c|c|c|c|}
\hline \multirow[t]{2}{*}{ Ratio (waste: binder) } & \multirow[t]{2}{*}{ Thickness $(\mathrm{cm})$} & \multicolumn{3}{|l|}{ Texture } \\
\hline & & Coarse & Medium & Fine \\
\hline \multirow[t]{3}{*}{$1.0: 2$} & 0.5 & $\checkmark$ & $\checkmark$ & $\checkmark$ \\
\hline & 1.0 & $\checkmark$ & $\boldsymbol{v}$ & $\checkmark$ \\
\hline & 1.5 & $\checkmark$ & $\checkmark$ & $\checkmark$ \\
\hline \multirow[t]{3}{*}{ 1.0:0 } & 0.5 & $\checkmark$ & NA & NA \\
\hline & 1.0 & $\checkmark$ & NA & NA \\
\hline & 1.5 & $\checkmark$ & NA & NA \\
\hline \multirow[t]{3}{*}{ 1.0:1 } & 0.5 & $\checkmark$ & $\checkmark$ & $\checkmark$ \\
\hline & 1.0 & $\checkmark$ & $\checkmark$ & $\checkmark$ \\
\hline & 1.5 & $\checkmark$ & $\checkmark$ & $\checkmark$ \\
\hline \multirow[t]{3}{*}{$1.5: 1$} & 0.5 & $\checkmark$ & $\checkmark$ & $x$ \\
\hline & 1.0 & $\checkmark$ & $\checkmark$ & $x$ \\
\hline & 1.5 & $\checkmark$ & $\checkmark$ & $x$ \\
\hline \multirow[t]{3}{*}{$2.0: 1$} & 0.5 & $\checkmark$ & $\checkmark$ & $x$ \\
\hline & 1.0 & $\checkmark$ & $\checkmark$ & $x$ \\
\hline & 1.5 & $\checkmark$ & $\checkmark$ & $x$ \\
\hline
\end{tabular}

$N A$ not available because pineapple waste of that ratio could not be ground into medium and fine textures

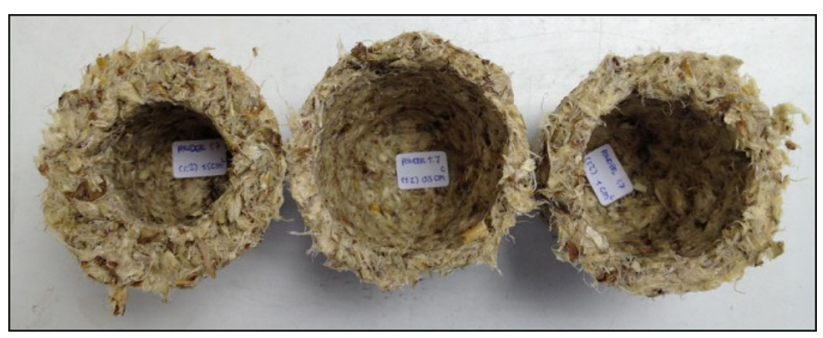

Fig. 2 Thickness of decomposable pots, from left: 1.5, 0.5 and $1.0 \mathrm{~cm}$

texture. The remaining ratios had decomposition times of less than 45 days.

\section{Ratio of nutrient release}

The combinations of pineapple waste to binder ratio, texture and thickness used in this study are shown in Table 3.

This study compared the emission of nitrogen at different ratios; for the formula, a significance level of 0.05 was chosen to indicate differences. Formulas 4, 11 and 12 averaged $0.340,0.485$ and $0.350 \%$ nitrogen, respectively, and were not different from each other but were different from the other formulas. The nitrogen content of formula 11 was different from the other formulas. The average percent nitrogen is shown in Table 3 .

This study also compared the emission of phosphorus during degradation at a significance level of 0.05. Formulas 11 and 10 averaged 7.97 and $7.06 \mathrm{mg}-\mathrm{P} / \mathrm{kg}$, 
Table 3 Degradation, nutrient release, absorption and evaporation properties of decomposable pots

\begin{tabular}{|c|c|c|c|c|c|c|c|c|}
\hline Formula & Waste:binder & Texture & $\begin{array}{l}\text { Thickness } \\
(\mathrm{cm})\end{array}$ & $\begin{array}{l}\text { Degradation } \\
\text { (days) }\end{array}$ & $\begin{array}{l}\text { Total nitrogen } \\
(\%)\end{array}$ & $\begin{array}{l}\text { Total } \\
\text { phosphorus } \\
(\mathrm{mg}-\mathrm{P} / \mathrm{kg} \text { ) }\end{array}$ & $\begin{array}{l}\text { Absorption } \\
(\mathrm{ml})\end{array}$ & $\begin{array}{l}\text { Evaporation } \\
\text { (h) }\end{array}$ \\
\hline 1 & $1: 2$ & Coarse & 0.5 & $>45$ & $0.280 \mathrm{~b}$ & $5.645 \mathrm{de}$ & $181.06 \mathrm{f}$ & $408 \mathrm{c}$ \\
\hline 2 & & & 1.0 & $>45$ & $0.305 \mathrm{~b}$ & $6.125 \mathrm{cde}$ & $206.53 c$ & $408 \mathrm{c}$ \\
\hline 3 & & & 1.5 & $>45$ & $0.305 b$ & $5.935 \mathrm{de}$ & $186.62 \mathrm{ef}$ & $408 \mathrm{c}$ \\
\hline 4 & & Medium & 0.5 & $>45$ & $0.340 \mathrm{ab}$ & $5.450 \mathrm{de}$ & $136.98 \mathrm{hg}$ & $360 d$ \\
\hline 5 & & & 1.0 & $>45$ & $0.305 b$ & $6.240 \mathrm{~cd}$ & 191.71ed & $408 \mathrm{c}$ \\
\hline 6 & & & 1.5 & $>45$ & $0.305 b$ & $5.880 \mathrm{de}$ & $203.29 \mathrm{c}$ & $408 \mathrm{c}$ \\
\hline 7 & & Fine & 0.5 & $>45$ & $0.265 b$ & $5.760 \mathrm{de}$ & $125.82 \mathrm{i}$ & $360 d$ \\
\hline 8 & & & 1.0 & $>45$ & $0.305 b$ & $5.655 \mathrm{de}$ & 131.21hi & $360 d$ \\
\hline 9 & & & 1.5 & $>45$ & $0.265 \mathrm{~b}$ & $6.335 \mathrm{bcd}$ & $143.77 \mathrm{~g}$ & $360 d$ \\
\hline 10 & $1: 0$ & Coarse & 0.5 & $>45$ & $0.330 \mathrm{~b}$ & $7.060 \mathrm{abc}$ & $195.70 \mathrm{~d}$ & $408 \mathrm{c}$ \\
\hline 11 & & & 1.0 & $>45$ & $0.485 \mathrm{a}$ & $7.970 \mathrm{a}$ & $258.43 b$ & $444 a$ \\
\hline 12 & & & 1.5 & $>45$ & $0.350 \mathrm{ab}$ & $7.270 \mathrm{~b}$ & $267.64 a$ & $432 b$ \\
\hline 13 & $1: 1$ & Coarse & 0.5 & 45 & $0.310 \mathrm{~b}$ & $5.995 \mathrm{de}$ & - & - \\
\hline 14 & & & 1.0 & 45 & $0.280 \mathrm{~b}$ & $6.150 \mathrm{cde}$ & - & - \\
\hline 15 & & & 1.5 & 45 & $0.300 \mathrm{~b}$ & $5.700 \mathrm{de}$ & - & - \\
\hline 16 & $1.5: 1$ & Coarse & 0.5 & 36 & $0.285 b$ & $5.500 \mathrm{de}$ & - & - \\
\hline 17 & & & 1.0 & 35 & $0.295 b$ & $5.195 \mathrm{e}$ & - & - \\
\hline 18 & & & 1.5 & 31 & $0.305 b$ & $5.970 \mathrm{de}$ & - & - \\
\hline
\end{tabular}

Values followed by letters represent values of total nitrogen, total phosphorus, absorption and evaporation that are significantly different from the other measurements $(p<0.05)$

respectively, and were not statistically different from each other but were different from the other formulas. Formulas 12, 10 and 9 averaged 7.27, 7.06 and $6.34 \mathrm{mg}-\mathrm{P} / \mathrm{kg}$, respectively, and were not different from each other but were different from all other formulas. Finally, formula 17 averaged $5.20 \mathrm{mg}-\mathrm{P} / \mathrm{kg}$ and was significantly different from formulas $9,10,11$ and 12 . The average percent phosphorus is shown in Table 3.

Results indicated that the ratio of pineapple waste to binder, texture of the waste and thickness significantly affected emissions of nitrogen and phosphorus $(p<0.05)$. Moreover, in terms of horticultural performance, the biodegradable pots did not cause damage to the plants during the test period (Schettinia et al. 2013).

\section{Rate of absorption}

This study compared the absorption volume of different pot formulas, at time intervals of 35, 40 and $45 \mathrm{~min}$. A significance level of 0.05 was used to assess differences between of the formulas. Although all formulas were different, the best formula was 12 . The average absorption volume of the formula 12 pot in 5 min was 200.76, which was inversely proportional to the absorption time. In $40 \mathrm{~min}$, the total average absorption volume was 267.64. The 5-min absorption volumes for formulas 3 and 7 were
55.83 and 61.87 , respectively. These values were significantly different from the rest of the results and inversely proportional to the absorption time. Their average absorption volume in the 35 and 45 min trials were 125.82 and 131.21 , respectively.

The data revealed that, initially, the pots absorbed large quantities of water. Absorption gradually increased to a saturation point. The average rates of water absorption are shown in Fig. 3 and Table 3.

First, the adsorption rate depended on the texture and pore surface of the decompose pots because the cohesiveness between textures was different, as shown in Fig. 4 . Second, the decomposable pot extrusion process showed that the coordination of materials was different for each surface material. The coarse texture was not smooth. Its absorption rate was higher than that of the fine texture. The particles of water easily infiltrated through the texture pot. Third, the quantity of binder showed an inverse relationship with absorption rate. Lastly, water absorption depended on the size and number of gaps between particles (pores) in the texture.

\section{Rate of evaporation}

This study compared the evaporation time of the different decomposable pots, and significance was assessed at the 
Fig. 3 Water absorption test results

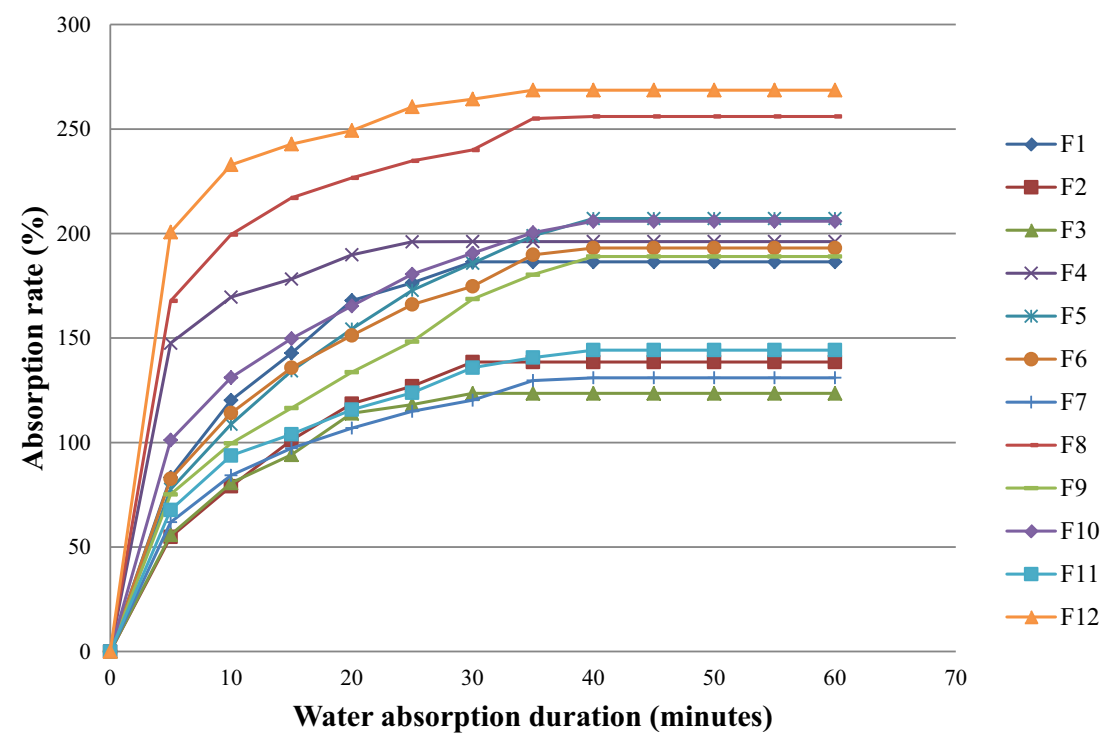

related to the time of evaporation $(444 \mathrm{~h})$. On the other hand, formulas 2, 3, 7 and 11 were not different from each other but were different from all other formulas. They averaged $34.54,45.24,38.79$ and 45.15 , respectively, and were inversely related to the time of evaporation $(360 \mathrm{~h})$.

The evaporation rate of water could not be measured directly, so it had to be measured by comparing the total amount of water evaporated from the material with the amount of water or weight lost each day. The study of evaporation rates revealed two main results. First, the air temperature at the surface affected the evaporation rate less than the time of evaporation at room temperature; the decomposable pots could absorb water and retain moisture for a period of 2-3 days. Second, the size of the surface textures affected the evaporation rate, as water in coarse-

Fig. 5 Evaporation test results

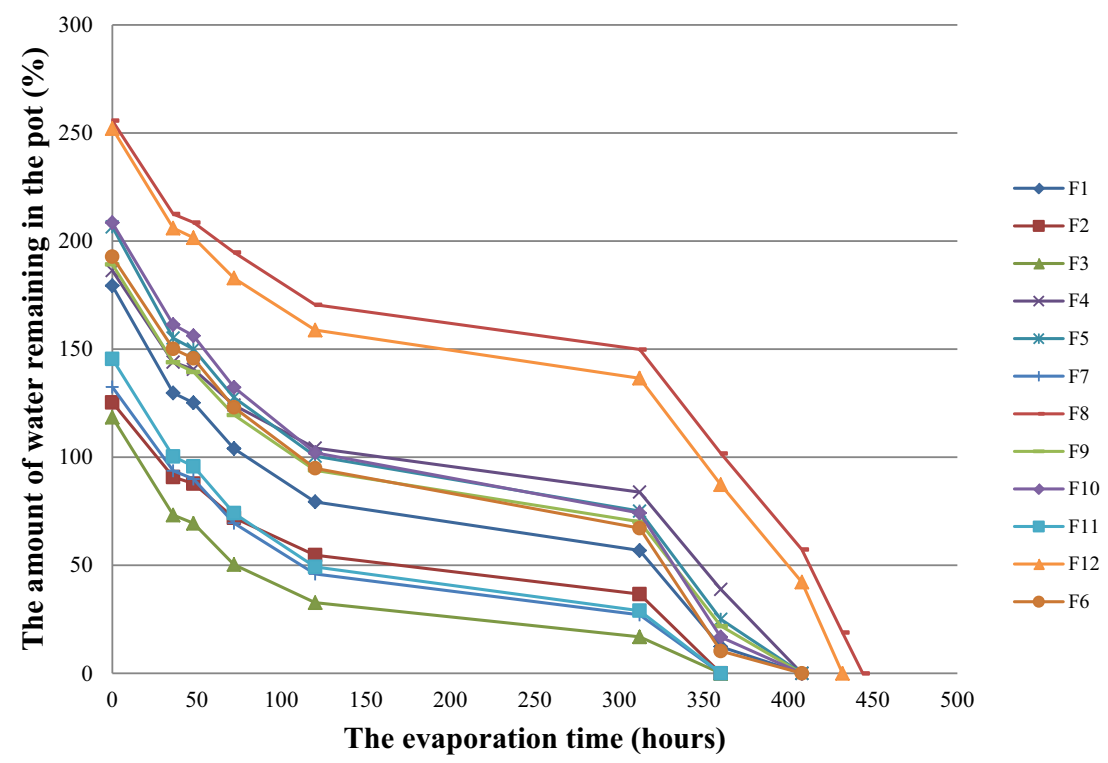


texture pots evaporated more slowly than water in fine texture pots, as shown in Fig. 5 and Table 3.

\section{Conclusions}

The results of this research showed that size of pineapple waste textures and pot thickness were different. Both significantly affected degradation, nutrient release, absorption and evaporation $(p<0.05)$. The most suitable formula included a 1:0 ratio of pineapple waste to binder, a coarse texture and a pot thickness of $1 \mathrm{~cm}$. Manufacturing pots using this formula successfully resulted in a decomposable pot with release rates of $\mathrm{N}$ and $\mathrm{P}$ of 0.34 and 7.97, respectively. The average volume of absorption was 267.64 in $40 \mathrm{~min}$. The average time of evaporation was $444 \mathrm{~h}$. The decomposition times were more than 45 days.

Moreover, the physical and chemical properties of pineapple waste (before and after pot production) were not harmful to the environment and were a benefit to crops. Furthermore, the study found that the cost of producing the products was low. First, the cost of production per pot for pineapple waste (fresh) at a three-and-a-half inch diameter was 0.0075 USD (excluding logistical costs). This case study showed the limitations of using pineapple waste. Thus, with a small volume of pineapple waste. Second, the cost of production per pot for dried pineapple waste at a three-and-a-half inch diameter was 0.03 USD (excluding logistical and energy costs).

Finally, using pineapple waste from the cannery industry to produce decomposable pots adds value to the byproduct and reduces disposal costs. Instead of using pineapple waste to produce ethanol, extracted fibers, paper products and decomposable pots could be alternative solutions to utilize pineapple waste (Schieber et al. 2001).

Open Access This article is distributed under the terms of the Creative Commons Attribution 4.0 International License (http://crea tivecommons.org/licenses/by/4.0/), which permits unrestricted use, distribution, and reproduction in any medium, provided you give appropriate credit to the original author(s) and the source, provide a link to the Creative Commons license, and indicate if changes were made.

\section{References}

Bremner JM, Mulvaney CS (1982) Nitrogen-total. Chemical and Microbiological Properties. the American Society of Agronomy Inc, Soil Science Society of America Inc, Madison, Wisconsin USA

Chandak SP (2010) Trends in solid waste management: management: issues, issues, challenges and opportunities. United Nations Environment Programme, Tokyo
Ch'ng HY, Ahmed OH, Nik SK, Majid MA (2013) Co-composting of pineapple leaves and chicken manure slurry. Int J Recycl Org Waste Agric 2:1-8. https://doi.org/10.1186/2251-7715-2-23

Espinosa RM, Torres P, Meneses MÁ, Viuda-Martos M (2012) Chemical, technological and in vitro antioxidant properties of mango, guava, pineapple and passion fruit dietary fibre concentrate. Food Chem 135:1520-1526. https://doi.org/10.1016/j. foodchem.2012.05.057

Food Intelligence Center Thailand (2015) Pineapple industry. National food Institute, Bangkok

Krinara A (2011) The production of flower pot by waste from palm oil extraction industry. The 3rd Walailak Research Conference, Thailand. Walailak University, Nakhon Si Thammarat, pp 257-264

Leach HW (1965) Gelatinization of starch. Starch, Chemistry and Technology. Academic Press, New York

Office of Agricultural Economics (2016) Agricultural statistics of Thailand 2016. Ministry for Agriculture and Cooperatives, Bangkok

Perez CB, Asian, Food PC, Center FT, Hsu CT (1973) Farm Byproducts and Beef Production. Asian and Pacific Council, Food and Fertilizer Technology Center

Pollution Control Department (2015) Thailand state of pollution report 2015. Pollution Control Department, Bangkok

Ritthisorn S, Jutakanoke R, Teeka J (2016) Production of pineapple peel handicraft paper from canned fruit industrial factory. Sci Tech RMUTT J 6(1):39-47

Schettinia E, Santagatab G, Malinconicob M, Immirzib B, Mugnozzaa GS, Voxa G (2013) Recycled wastes of tomato and hemp fibres for biodegradable pots: physico-chemical characterization and field performance. Resour Conserv Recy 70:9-19. https:// doi.org/10.1016/j.resconrec.2012.11.002

Schieber A, Stintzing FC, Carle R (2001) By-products of plant food processing as a source of functional compounds-recent developments. Trends Food Sci Technol 12:401-413. https://doi.org/ 10.1016/S0924-2244(02)00012-2

Sopunna K, Pasom W, Woradong K, Chaiwangrach A (2015) Fabrication and properties of biological plant pots SNRU. J Sci Technol 7:1-7

Srirod K, Piyachomkwan K (2003) Carbohydrate Technology, 2nd edn. Kasetsart University Press, Bangkok, Thailand

Sukaneeyuth P, Chaiarrekij S, Suvarnakich K (2014) Effect of fiber types on paper properties and printability. Proceedings of the 5th Hatyai National and International Conference, Thailand. Hatyai University, Songkhla

Thongpae S, Suwannarat C, Vacharotayan S, Chanchareonsook J (1992) Utilization of organic waste materials for calcareous soil improvement. Kasetsart University Press, Bangkok

Upadhyay A, Lama JP, Tawata S (2010) Utilization of Pineapple Waste: a Review. J Food Sci Technol Nepal 6:10-18

Utama-ang N, Tepjaikad T Extraction of dietary fiber from pineapple residue and utilization. In: Proceedings of the 39th Kasetsart University Annual Conference: Fisheries, Agro-Industry, Thailand, 2001. Kasetsart University, p 605

Youburee P (2003) Utilization of pineapple residues for fattening steers. Kasetsart University Press, Bangkok

\section{Publisher's Note}

Springer Nature remains neutral with regard to jurisdictional claims in published maps and institutional affiliations 